\title{
Education in Government Communications: Case of Ukraine
}

\author{
Ilchenko-Syuyva Lesya ${ }^{1}$, Riabtsev Gennadii ${ }^{2, *}$, and Tertychka Valerii ${ }^{3}$ \\ ${ }^{1}$ Kyiv Mohyla School of Governance, NaUKMA, Kyiv, Ukraine \\ ${ }^{2}$ Kyiv Mohyla School of Governance, NaUKMA, Kyiv, Ukraine \\ ${ }^{3}$ Kyiv Mohyla School of Governance, NaUKMA, Kyiv, Ukraine
}

\begin{abstract}
The article highlights building prerequisites that help to tackle problems related to the insufficient government communications and poor information provided to potential audiences in participatory democracies. The analysis has shown that many counties face the lack of strategic communications (both horizontal and vertical) and thus, create concerns about misunderstanding and bottlenecks in design and implementation of public policies. This problem expands when countries undergo rapid, systemic, fundamental changes, in particular due to the energy transition. Ukraine is not an exemption. Lack of real competition between MPA programs, pre-service and in-service training programs for public servants in Ukraine and poor quality of programs leave a niche for educational institutions to take the leading position. Hence, Kyiv Mohyla School of Governance (hereinafter - KMSGov) launched very specific and need oriented MPA program in Government Communications. The program was designed in close cooperation with Ukrainian public authorities and become client oriented. The program is innovative and one of a kind due to its integrity and consistency. It is student-centered and widely uses case studies, simulations and PBL techniques. In addition, the program consists of logically interconnected courses, which complement each other and provide broad pattern of particularities of evidence-based public policy design and implementation, public administration and management theory and practice, modern features of government communications and policy advocacy. Due to COVID restrictions and worldwide lockdown the Government Communication MPA program provided by KMSGov was fully transferred into on-line format without losing its quality. It became possible due modern information and communication technologies (tested in February-July 2020). The paper provides brief overview and main results of the analysis of the existing MPA programs and key particularities of the newly launched program.
\end{abstract}

Keywords: good governance, rule of law, democratic society, public authorities, policy making, government communication, education programs, curricula, qualifications.

\section{Introduction}

As the reputed fourth estate, news media are seen as the conduit of informed citizenship in participatory democracies. Yet evidence that journalists are failing in this pivotal role is rapidly accumulating across the world [1]. There is a persistent decline in the size of traditional news audiences, little indication that the news industry is effectively coping with economic and technological challenges, and journalists are facing challenges to their authority and credibility in an era where the label fake news is generously evoked in response to mainstream news. Trust in media institutions among citizens has been on the decline. Given these trends, it is not surprising that citizens are turning to alternative sources of information while governments, individual politicians, and special interest groups are bypassing news media and communicating directly with citizens through social media.

While the shift in information flow is significant, traditional news media are still a cornerstone in the dissemination of information, particularly among citizens who are active participants in democratic processes [2]. Public agendas and opinions arise from the interaction between messages designed by government communication specialists, journalistic filtering and dissection of those messages, and the feelings and understanding citizens have about news media and those in office. In this contentious dynamic neither the news media, neither politicians, nor citizens want to be under another's control. For example, journalists ward off attempts by government spokespeople to control the framing of public issues by revealing and criticizing political strategies, while politicians and their spokespeople often accuse the news media of distorting

\footnotetext{
*orresponding author: rgl2006@ukr.net
} 
the messages they want conveyed to citizens - who in return show their disapproval of both institutions through apathy and low voter turnout during elections [3]. Despite such tensions, all sides are compelled to cooperate in a symbiotic relationship. In particular, news is created through the joint efforts of journalists and government spokespeople - despite the direct access that politicians might have to citizens through social media. As scholars often observe, politicians cannot succeed without access to the media, just as reporters cannot succeed without access to political leaders.

Easier access to information creates stable social demand for restructuring transition economies in accordance with "world standards" of consumption. However the environment is deteriorating as more and more fossil fuels are used to meet this demand. Living standards decline, while outgoings on environmental protection, health care, and social security are increasing. The use of renewable energy can be the solution. However, effective demand for "green" energy in transition economies can appear only if it becomes cheaper.

The high cost of new technologies and the inability of traditional energy to "ensure access to affordable, reliable, sustainable and modern energy for all" [4] deepens energy poverty and spreads "energy democracy". Consumer behavior is evolving rapidly. They develop their own, human-centered energy systems. In such systems, energy consumers are simultaneously energy suppliers (prosumers), since they do not want to depend on energy monopolists and outdated networks [5]. An "energy transition" is taking place. It focuses on distributed capacities, "smart" grid, and highly competitive decentralized markets.

However, the energy transition will not only require policy switch from attempts to stop aging of traditional systems and the constant growth of tariffs, to flexible energy systems; paternalistic policy should be substituted by active position of citizens and energy efficient consciousness. All the above mentioned create an urgent need in highly skilled professionals who have Master of Public Administration (hereinafter - MPA) degrees and possess explicit knowledge and competences in government communications. It will allow overcoming substantial bottlenecks in public policy advocacy, rule of law, design and implementation of ethic and moral norms and codes, enhancing social values and bonding.

\section{Problem and methods}

In 2016 the Concept Paper on Reforms in Government Communications was adopted in Ukraine [6]. In the Concept Paper the following problems and urgent issues were defined:

- lack of the incorporated system of government communications;

- public procedures do not meet current needs;

- lack of strategic communications (routine operations of public servants limited to tactical activities that are focused on dealing with current issues;
- lack of forecasting and strategic planning that is based on demand and public needs;

- incomplete internal communications and lack of cooperation between executive bodies and corresponding departments;

- central executive bodies are focused on providing public with just their own information which is not all the time correspond with disseminated by the government;

- insufficient public understanding of government policies;

- absence of inclusive system of sharing knowledge and skills, integrated data base - each public authority have to start processes from the very beginning.

Structural units (individual officials, departments, administrations, units, sectors), which are responsible for setting the system and government communications are substantially different. At the same time, usually the main focus of these units is public relations, presentation of public authorities in mass media, etc.

To resolve all the above problems public authorities will need highly qualified specialists who possess general and special (professional) competences in the area of government communications on all levels of the public administration system.

Government communication and its distinctive features are not covered in either pre-service or in-service educational programs in Ukraine. Consequently, there is an urgent need for new track within master of public administration programs.

To form this track, the authors set the following objectives:

- to conduct a comparative analysis of MPA programs, pre-service and in-service training programs for public servants in Ukraine and identify their common bottlenecks;

- to generalize obtainable curricula of MPA in strategic communications offered in Ukraine;

- to synthesize Ukrainian approaches to training new generation of public servants, providing knowledge and skills based on the rule of law and empowered civil society;

- to check up the accuracy of scientific approaches to program design and development on practice, in particular during COVID restrictions and worldwide lockdown.

\section{Data and analysis}

In Ukraine MPA programs are provided by 80 higher educational institutions. The main target groups of these MPA programs (Public Administration and Management) are acting and potential public servants. These programs formed the initial pool for qualitative data to conduct comparative analysis.

The results of the analysis showed that none of these institutions focuses on competences related to explicating government decisions, public policy advocacy, and legitimization of public decision making, public policy presentation, ensuring social values, social bonding, and relations. 
To some extent government communication obtain minor attention. Getting knowledge and skills in corresponding area is artificially combined with getting general and professional competencies in the field of:

- business communication

- declamatory skills

- communication technologies

- warning and resolving group conflicts

- public relations

- presentation of research results

- presentation of intellectual products

Such stage of training in government communication may be explained by insufficient understanding of what government communications in Ukraine is, low insight of its sense, as well as flaw of integrated standards of MPA programs [7]. As a result Ukrainian higher educational institutions offer their own MPA programs and independently decide on competencies and training results. The final decisions are made by the institutions mainly on the basis of traditions and foremost profile of the department (unit) responsible for MPA program. It may be public administration, management, business, economics, finance, law, sociology, political science, philosophy, psychology, etc.

Having in mind this fact the professional competencies that are related to the area of government communications can be described as following.

- Ability for building social interaction, cooperation, warn and resolve conflicts (the same as in social work and social security) (National Technical University of Ukraine "Kyiv Polytechnical Institute named after Igor Sikorskyi");

- Ability for presenting research results in different genres (Higher Educational Institution "Inter Regional Academy of Personnel Management); the same as in philology (State Higher Educational Institution "Lugansk National University named after Taras Shevchenko");

- Ability for communicating in Ukrainian and European languages in oral and/or written form (is common for all humanities) (National University of Life and Environmental Sciences of Ukraine);

- Ability for interpersonal communication (Kyiv International University);

- Ability for using effectively modern communication technologies (National Academy of Public Administration);

- Ability for representing public authorities (National Technical University of Ukraine "Kyiv Polytechnical Institute named after Igor Sikorskyi”);

- Ability for being open for communication and open in professional activity (National University of Life and Environmental Sciences of Ukraine);

- To be able to use instruments of mass and personal communications, to arrange public relations, to prepare and present intellectual products (Higher Educational Institution "Inter Regional Academy of Personnel Management);

- Ability for providing information in oral and written format, which is acceptable by the target audience (the same as statistics) (Kyiv University named after Borys Grinchenko);
- Ability for adjusting to the informational environment, which is related to public policy design in various areas of communications (Odesa Regional Institute of Public Administration);

- Ability for managing communications of companies/firms with the accent on anti-crisis and internal public relations, PR with use of modern technologies in mass media communications B2B, B2C, B2G, G2B, SMM (Odesa Regional Institute of Public Administration).

Program (educational) results of MPA programs it is stated that the acquirement should be focused on the ability for:

- communicating effectively in the area of public administration and public management on the bases of social responsibility, legal and ethical norms (National University of Life and Environmental Sciences of Ukraine),

- communicating effectively (National University of Life and Environmental Sciences of Ukraine) [8],

- maintaining dialog with researchers, academics and public (Dnipro Regional Institute of Public Administration),

- setting and maintaining cooperation and partnership (National University of Life and Environmental Sciences of Ukraine).

Some educational institutions (i.e. Higher Educational

Institution "Inter Regional Academy of Personnel

Management) focus on the following as program results:

- ability for understanding value of communications as a part of professional activity,

- understanding of ethical norms and rules of communication and ability to interact using means of verbal, non-verbal, and IT communication,

- knowledge and skills needed for work with mass media and public opinion.

To achieve these results the institutions brought in the following modules/courses:

- Communications in Public Administration,

- Public Communication and Professional Language in Public Administration,

- Social Interaction and Communication in Public Administration,

- Public Communication,

- Communication Activities in Public Administration,

- Information and Communication in Public Administration.

Usually, one of the above mentioned courses (4 to 8 ECTS credits) is a mandatory course in the curriculum. Though, some educational institutions (i.e. Lviv Regional Institute of Public Administration) include them to the list of electives.

The contents of the Communications in Public Administration course usually foresee the following topics (i.e. National Academy of Public Administration, or Poltava National Technical University named after Yuriy Kondratyuk):

1. Types, classification of theories of communication and communication activities in public administration and management; retrospective of formation and development; main notions and categories; design of contemporary theories of communications and new 
ideas in communication of public administration and management; requirements and responsibility for the results; principles and fundamentals.

2. Role of communications and communication activity; communication as a multi-channel system of interaction, communication skills; methodology, methods, types, technologies, techniques of communication; classification; cases of public communications.

3. Strategies, plans in public administration and management; foreign experience; up-to-date tendencies; principles; goals; decisions; rules; measures, communication policy; communication strategy; communication strategy and action; coordination of communication policy; policy of government external communication; communication strategy of public; national communication strategy; regional communication strategy; communication strategy of public bodies.

4. Methodology, methods, forms, technologies, techniques of public engagements to policy design and implementation and consolidation of the society; other countries' experience; theories, concepts, models; public participation in resolving social problems; creating public support to government policies and government decisions.

5. HR; individual and group leadership.

6. Place and role of public communications in public administration; organizational fundamentals of functioning of the communication departments in central and local public authorities; key communication techniques for press services of public authorities; communication mechanisms to create positive image of public authorities.

The contents of the Public Communications and Business Language in Public Administration course (i.e. National Academy of Public Administration, Cherkassy National University named after Bogdan Khmelnytskyi, National University of Water Management and Nature Resources) usually contain the following topics:

1. Fundamentals of the theory of communication; principles and main goals of communication in public administration.

2. Communications in public administration; types of communication and communication liaisons in public administration; public communication, forms and genres; informational and communicational support of subjects of public administration; survey in public decision making; strategic planning in PR; communication management; communication campaigns, tools and technologies.

3. Design and implementation of communication policy, its modern stage, main tendencies and priorities for development; navigation in communication flows; interaction with mass media; public consultations; web-technologies in public communication and communication with NGOs; fundamentals of public relations; types of direct contacts between government bodies and mass media.

4. Norms of business verbal etiquette; documentary design of government decisions, work with correspondence; conceptual fundamentals of business language in modern conditions.

5. Contemporary verbal communication in public administration; verbal communication in public administration in individual and group communications; communication aspects of the activities of public bodies under the conditions of crisis.

6. Public relations as communicational aspect of public administration; modern system of linguistic, sociolinguistic and pragma-linguistic knowledge about structure, patterns and phenomena of language and inter-language behavior in different situations.

7. Declamation in public administration; tools of declamation; culture of negotiation, polemic rules, techniques and tactics; conversation, discussion, debates, business meetings, interviews. Verbal and non-verbal tools to be used during discussions, debates, business meetings, interviews, public presentations, conversations.

The contents of the Communications in Public Sphere course (i.e. Kharkiv Regional Institute of Public Administration, Lviv Regional Institute of Public Administration, KROK University) usually contain the following topics:

1. Retrospective of communication theories; role and place of communication in a society; functions of communication; theory and practice of communication; information as a part of communication.

2. Typology of communication: types, levels, forms; main types of communication: material, genetic, psychological, social; role of language in verbal communication; non-verbal communication; micro-, midi- and macro communication; interpersonal, group and mass communication.

3. Characteristics of main types of communication; elementary elements of communication; types of communication; subjects of communication; forms of communication; dialog from the prospective of communication.

4. Communication channels and barriers; types and characteristics of main communication channels; selection and use of communication channels; classification, characteristics, methods and technologies of overcoming communication barriers.

5. Communication models and methods of analysis; methods and forms of communication analysis; content analysis; political analysis.

6. Communication technologies; propaganda, advertisement, PR ; content and functions of political propaganda; methods of political PR; political image making; informational and communication activities in the political process; political and informational lobbying; communication campaigns.

7. Mass society, mass information, mass culture; main models of mass communication.

8. Mass media in communication and information; main types and channels; methods and forms to impact mass consciousness; theory of social responsibility of mass media; relations between mass media, government and public; Internet and globalization of 
communication; types and forms of public presentations: speech, report, disclosure, review.

9. Social communication; social communication: types, levels, forms; communication needs of individual, social groups, society; organization of modern models of a society; social implementation of information; public opinion.

10. Political communication; content and external effects; main theories, subjects and objects, political technologies: political advertisement, propaganda and informational lobbying; image of a political leader.

11. International and cross-culture communication; international information campaigns; globalization of mass communication and international relations; integration processes in mass media; culture as a type of communication; cross-cultural relations.

The analyzed curricula show that none of the existing MPA programs offered in Ukraine in 2018/2019 academic year do not guarantee getting general and professional knowledge and skills needed to tackle problems that have been highlighted in the Concept Paper of Public Communication Reform [6].

There exist a number of training limitations in the area of strategic communications in the framework of creation and implementation of the system of strategic communications in the area of national security and defense [9]. Education in this area is limited to short-term in-service courses that are focused mainly on understanding of strategic communications phenomena and use of its certain components. Unfortunately, these programs can't be described as systemic, consecutive and logical. Moreover, understanding of key components of strategic communications in Ukraine does not always correspond to what is set by NATO Strategic Communication Policy [10].

The only Ukrainian higher educational institution which trains MPA students in Strategic Communications is Odesa Regional Institute of Public Administration.

Also, few Ukrainian higher educational institutions (i.e. Kyiv University named after Borys Grinchenko, Kyiv National University named after Taras Shevchenko, etc.) have initiated new track - Communication and Journalism [11]. Though, such a mix is doubtful, because the list of general and special competences in journalism and public communication differs a lot [12].

The conducted analysis gives us a possibility to make the following conclusions:

1. Despite the increasing need in highly skilled specialists in public communications, non out of 80 Ukrainian higher educational institutions, which offer MPA programs thrash out all needed competences.

2. Ukrainian society and public authorities have no common understanding and fixed definition of that public communication is about. Thus, Ukrainian higher institutions filled in the gap with their own vision basing on their profiles, syllabus and traditions.

3. Getting competencies in public communication is usually combined with business and interpersonal communications, communication technologies, warning and resolving conflicts, public relations, declamation and presentation of intellectual products.

4. The contents of courses that are linked to competencies in public communications not always correspond to their names/titles.

5. The length of courses that to some extend are linked to competencies in public communications is insufficient to get good results.

6. Taking any course in the existing programs does not guarantee getting general and professional competencies needed to resolve problems that have been highlighted in the Concept Paper of Public Communication Reform [6].

The transparency of competition for positions in public service promoted by the National Agency of Ukraine on Civil Service has demonstrated gaps in the knowledge and skills among applicants for service category A (the top public servants), as well as newly hired public servants in lower category positions. Lack of competence and poor understanding of the particularities and procedures of public administration have challenged these individuals ability for being engaged in effective and efficient government leadership and to implement reforms in the country on the principles of good governance. This lack of real competition among the existing educational institutions in pre-service and inservice training for public servants in Ukraine and the generally poor quality of the programs have made it impossible to determine the real needs in knowledge and skills training, which programs should meet by curricula, contents of courses and in the most suitable form. These factors have led to low motivation of public servants, who might apply for MPA and in-service training programs.

\section{Proposed decision}

Lack of real competition among providers of MPA, preservice and in-service training programs for public servants in Ukraine and poor quality of programs leave a niche for potential providers. KMSGov took an opportunity, developed and launched a very specific and need oriented MPA program in Government Communication. The program was designed in close cooperation with Ukrainian public authorities. The goal of the Program is to educate and train public servants of various levels and those, who would like to enter public service to meet requirements stipulated by the Law of Ukraine on Public Service and get them ready to perform in the best way possible in communicating and advocating public policies in various areas and levels of public administration in Ukraine.

The main idea of the MPA program delivered by KMSGov is to combine theoretical fundamentals and extensive practical training. This will allow to equip acting public servants and new generation of public servants with the knowledge and skills grounded on the rule of law and empowered civil society.

Training the pool of highly qualified professionals is crucial for the system of public administration and its further development. One of the main tasks of the 
democratic society is to cultivate respect for human dignity and rights in public-private interaction.

The main purpose of the developed program is to train professional public servants, who think strategically, have policy-making skills and are able to govern. In contrast to the current programs, knowledge, skills and abilities formed by MPA grogram offered by KMSGov fully corresponds to the professional standards of civil servants approved by the National Agency of Ukraine on Civil Service.

Students gain these knowledge, skills and abilities by taking five mandatory courses:

- English for Professional Needs;

- Philosophy of Democratic Governance;

- Research Methods for Government Communication (with modules Methods for Social Research, and Methods for Policy Analysis);

- Evidence-based Policy-making (with modules Policymaking Process, Policy Analysis, Economics for Public Policy, and Public Finance and Budgeting);

- Strategic Public Management \& Communication (with modules Change Management, Strategic Management \& Planning, and Strategic Communications).

They also elect between the 15 professional courses they need: Propaganda, Media Influences and Critical Thinking; The Rule of Law, Rule-making \& Enforcement; Media Law; Mediation and Dialogue Facilitation as Tools of Democratic Governance; Social Media for Strategic Communications; Data Visualization \& Graphic Design; Communications campaigns; Multilevel Governance and Communication; Comparative Analysis of Government Communication; Communicative Support for Public Policy (Advocacy Policy); Monitoring and evaluation for Government Communication; Human Capital \& Ethics in Government Communication; Cooperation between Government, Business, and Civil Society; Public Diplomacy; Communication Project \& Time Management; and Digital Democracy, Technology \& Data Security in Communication.

All education goals of the MPA program offered by KMSGov are developed and implemented as holistic, consistent, end-to-end, interactive educational algorithm. It consists of:

- motivation presentation focused on an issue in Government Communications as a professional entrance exam;

- a number of policy study and policy analysis papers throughout the study (the policy area is chosen by the student). The outline for drafting policy paper include separate components that are covered by a number of courses;

- drafting a strategic plan for the independently chosen by the student policy actor and essays on change management (The outline for drafting policy paper include separate components that are covered by a number of courses);

- Communication Strategy Design as Capstone Project based on a topic independently chosen by the student. It incorporates certain components from policy paper and policy recommendation part, which have to be tested during internship in corresponding Ukrainian public authorities.

All mandatory courses and electives of the MPA program are mutually consistent, complementary and focused on the implementation of a holistic, consistent, interactive educational algorithm. For example, the policy paper making algorithm is formed by the Evidence-based Policy-making course, which is mandatory. The methodological basis for drafting policy paper is provided in Research Methods for Public Governance course. Furthermore, the algorithm is supplemented by The Rule of Law, Rule-making and Enforcement, Economics for Public Policy, Public Finance and Budgeting courses. Students can increase the practical orientation of their policy papers by choosing electives Stakeholder Analysis \& Policy Environment, Economic and Political Aspects of Policy Analysis, Socio-Psychological and Ethical Aspects of Policy Analysis and Evaluation etc. The algorithm for drafting forecast and program documents, in addition to the above, is formed in Change Management, Strategic Management and Planning, and Strategic Communications courses.

To form additional professional competencies in the chosen field of future professional activity, students can improve their skills by:

- taking courses, separate modules, guest courses they need from the list of several hundred courses listed in the individual e-office and master them individually in person or remotely on the DistEdu e-learning platform;

- independently acquire knowledge, develop skills and abilities, using open access to educational materials on the official website of the KMSGov, using the capabilities of the automated library and information system ALEPH and Kyiv Mohyla institutional repository eKMAIR.

The MPA program offered by KMSGov is innovative due to:

- compliance of competencies, knowledge, skills and abilities with professional standards of civil servants, approved by the National Agency of Ukraine on Civil Service;

- integrity, consistency, permeability, interactivity of the educational algorithm, where courses as structural components are interconnected and complement each other;

- co-teaching of courses on the principles of interdisciplinarity, highly qualified full-time lecturers, wide involvement of well known practitioners, guest lecturers (politicians, civil servants, local government officials - topical meetings for one or two couples);

- ensuring the right of student to independently form his/her list of electives of the program and attract guest lecturers;

- possibility of full transfer to blended (distance) learning mode without losing quality of the program, due to modern information and communication technologies (tested in February-July 2020 after the introduction of quarantine restrictions in Ukraine). The program is: 
- $\quad$ student-centered - involves focusing on stimulating maximum activity of students, expanding their autonomy and strengthening responsibility;

- problem-oriented - focuses on the real social problems as objects of study, processes and phenomena and ways of solving them;

- result-oriented - involves the development of skills of independent selection of tools and ways to solve theoretical and real social issues;

- focused on the development of skills of independent search of theoretical, normative and other sources of information that are necessary for critical assessment and formulation of relevant conclusions and drafting recommendations.

The predominant methods and ways of learning are active (problem-oriented, interactive, project, research, information): lectures-conversations that have an interactive scientific and cognitive nature, multimedia classes, distance learning, presentations, discussions, case studies, business, role-playing and simulation games, public hearings, work in mini-analytical groups, brainstorming, search for solutions, projects, research seminars, independent work, research practice. Instruction is focused on personal development, group work, the ability to present its results, which contributes to the formation of understanding of the need and willingness to continue lifetime learning.

\section{Conclusion}

1. At present Ukraine faces lack of strategic communications in public administration system: routine operations of public servants are limited to tactical activities, which are focused on dealing with current issues; the lack of forecasting and strategic planning based on demand and public needs, and poor public understanding of government policies.

2. This problem expands when countries undergo rapid, systemic, fundamental changes, in particular due to the energy transition.

3. To resolve these problems Ukraine need highly qualified specialists who possess general and special knowledge and skills in the area of government communications on all levels of public administration system.

4. The analysis showed that none out of the 80 MPA programs provided by Ukrainian higher educational institutions develops all needed competences in the area of government communications.

5. Therefore, KMSGov designed and launched MPA program in Government Communication. Its main goal is to prepare public servants to perform according to the recent requirements of the Law of Ukraine on Civil Service. The main idea of the MPA program offered by KMSGov is to combine theoretical background and extensive practical training and by this to equip acting public servants and new generation of public servants with the knowledge and skills grounded in the rule of law and an empowered civil society.
6. The program is innovative and one of a kind due to its integrity, consistency, permeability. It is studentcentered and use case studies, simulations and PBL techniques. The program consists of interconnected courses that complement each other and provide a broad horizon of evidence-based public policy making, public administration and management, modern specificity of government communications and policy advocacy. It is co-thought by academic staff and acting policy makers and policy communicators. Due to COVID restrictions and lockdown the MPA program provided by KMSGov was fully transferred into on-line format without losing its quality. It became possible due modern information and communication technologies (tested in February-July 2020).

7. The proposed Government Communication track will strengthen the current MPA program and provide practical focus that will serve the majority of students enrolled in the MPA program who are either current public servants or potential public employees. The knowledge and skills obtained through the new track will certainly be advantageous to students who aspire to government employment.

\section{Acknowledgements}

This article was elaborated as one of the findings in the framework of the University Partnership for Pre-Service and In-Service Training in Government Communications Project, implemented jointly by the Indiana University (Bloomington, USA) and National University of KyivMohyla Academy (Kyiv, Ukraine).

\section{References}

1. D. Owen, The Age of Perplexity: Rethinking the World we Knew. Radically Reassessing The Economic. Madrid, BBVA, OpenMind, Penguin Random House Grupo Editorial (2017). https:/www.bbvaopenmind.com/wpcontent/uploads/2018/03/BBVA-OpenMind-DianaOwen-The-New-Medias-Role-in-Politics.pdf

2. A. Mitchell, and J. Holcomb, State of the News Media. Research Report. Washington, D.C.: Pew Research Center (2016).

https://assets.pewresearch.org/wpcontent/uploads/sites/13/2016/06/30143308/state-ofthe-news-media-report-2016-final.pdf

3. D. A. Graham, Alternative Facts: The Needless Lies of the Trump Administration. The Atlantic (January 22, 2017).

https://www.theatlantic.com/politics/archive/2017/01 /the-pointless-needless-lies-of-the-trumpadministration/514061

4. Sustainable Development Goal 7. UN (2018). https://www.un.org/sustainabledevelopment/energy/

5. Accelerating access to sustainable energy: A key priority in energy transition. Global Future Council on Energy (2019). 
http://www3.weforum.org/docs/WEF_Accelerating access_to_sustainable_energy.pdf

6. Concept on Reforms in Government

Communications. The Ministry of Information Policy of Ukraine: official website. (January 22, 2016).

https://mip.gov.ua/cr/documents/56.html [in Ukrainian]

7. Approved standards of higher education. The Ministry of Education and Science of Ukraine: official website. (November 3, 2020). https://mon.gov.ua/ua/osvita/visha-osvita/naukovometodichna-rada-ministerstva-osviti-i-naukiukrayini/zatverdzheni-standarti-vishoyi-osviti [in Ukrainian]

8. On approval of requirements for professional competence and business reputation of officials of the State institution Energy Efficiency Fund. Decree \# 138. (February 28, 2018).

https://zakon.rada.gov.ua/laws/show/138-2018$\% \mathrm{D} 0 \% \mathrm{BF} / \mathrm{conv} \# \mathrm{Text}$ [in Ukrainian]

9. For the first time, an optional course in strategic communications is being held at the National University of Defense of Ukraine. The Ministry of Defense of Ukraine: official website. (December 20, 2017). https://www.mil.gov.ua/news/2017/12/20/unaczionalnomu-universiteti-oboroni-ukraini-vpersheprovoditsya-fakultativnij-kurs-zi-strategichnihkomunikaczij/ [in Ukrainian]

10. NATO Strategic Communication Policy. SG(2009)0794 (2009). https://info.publicintelligence.net/NATOSTRATCOM-Policy.pdf

11. Reform of Government Communications involves the introduction of a new field of knowledge communicative studies. The Ministry of Information Policy of Ukraine: official website. (November 3, 2017). http://mip.gov.ua/news/2058.html [in Ukrainian]

12. O. Kushnir, and Y. Maksymenko. Contents of Strategic Communications in Modern Ukrainian State Building. GOAL (2016). http://goalint.org/zmist-strategichnix-komunikacij-usuchasnomu-ukrainskomu-derzhavotvorenni/ [in Ukrainian] 